\title{
Kernos
}

Revue internationale et pluridisciplinaire de religion grecque antique

9 | 1996

Varia

\section{José Carlos BERMEJO BARRERA, Mitología y mitos de la Hispania prerromana I}

\section{Véronique Krings}

\section{(e) OpenEdition \\ Journals}

\section{Édition électronique}

URL : http://journals.openedition.org/kernos/1191

DOI : 10.4000/kernos. 1191

ISSN : 2034-7871

\section{Éditeur}

Centre international d'étude de la religion grecque antique

Édition imprimée

Date de publication : 1 janvier 1996

ISSN : 0776-3824

\section{Référence électronique}

Véronique Krings, « José Carlos bermejo barrera, Mitología y mitos de la Hispania prerromana I 》, Kernos [En ligne], 9| 1996, mis en ligne le 21 avril 2011, consulté le 23 septembre 2020. URL : http:// journals.openedition.org/kernos/1191; DOI : https://doi.org/10.4000/kernos.1191 


\section{Comptes rendus et notices bibliographiques}

\section{José Carlos Bermejo BARRera, Mitología y mitos de la Hispania prerro-} mana I, 2da edición aumentada, Madrid, Akal, 1994 [1982]. 1 vol. 13,5 x $22 \mathrm{~cm}, 181$ p. ISBN : 84-460-0281-7.

Le présent ouvrage est la seconde édition d'un volume publié en 1982. En 1986, son auteur a en outre rassemblé, sous le même titre (II, 276 pp.), des études personnelles ainsi que celles d'autres savants. Celles-ci se caractérisent tant par la problématique commune qui y est abordée que par l'esprit dans lequel elles sont conçues : J.C. Bermejo Barrera entend prendre en considération à la fois les mythes propres aux peuples indigènes de la péninsule ibérique et ceux que d'autres, les Grecs surtout, ont élaborés, en ayant comme lieu de référence cette entité géographique. C'est en fait la confrontation populations indigènes / mentalité classique, avec un intérêt particulier pour la mythologie de l'Espagne pré-romaine, qui est au cœur du propos.

Cette nouvelle édition se distingue par l'ajout d'un chapitre, « La geopolítica de la embriaguez en Estrabón » [cf. La géopolitique de l'ivresse dans Strabon, in DHA, 13 (1987) p. 115-145]. Celui-ci s'inscrit dans le cadre d'une réflexion que J.C. Bermejo Barrera poursuit sur le discours strabonien relatif au barbare, plus particulièrement aux populations pré-romaines du nord-ouest de la péninsule ibérique. Ici, c'est un passage où sont rapportées les normes en vigueur en matière de consommation du vin et de manières de la table (Strabon, III, 3, 7) qui est discuté. Selon l'auteur, en dépit de ce qu'ont avancé d'illustres prédécesseurs comme A. Schulten ou J. Caro Baroja, Strabon ne peut être sollicité pour établir l'existence d'une institution particulière. Si on adhère au constat dressé au début de ce chapitre, à savoir que la critique moderne réduit traditionnellement la validité d'une source, en terme de « réalité historique », à la question de la sincérité de son auteur, alors qu'un tel principe méthodologique, qui néglige certaines composantes du discours historique, est insuffisant, la démonstration elle-même ne convainc pas totalement, ni dans le détail, ni par la méthode employée. La présentation des passages de la Géograpbie où il est fait référence au vin et à la vigne est intéressante mais trop vague, et il en va de même pour l'évocation des conceptions classiques ayant trait au symposion et à l'ivresse. En somme, alors qu'il constitue le point de départ de la réflexion, le texte de Strabon demeure insuffisamment étudié (l'édition du texte grec, sans accent, avec plusieurs fautes de grec, sans renvoi à une édition - $c f$. aussi p. $54, \mathrm{n} .51$ - laisse perplexe). On a le sentiment que J.C. Bermejo Barrera, tout soucieux de cerner au plus près le schéma mental de Strabon, de même que son implication dans la Géographie et sa place dans le monde contemporain - "historien de l'espace », le géographe est occupé à justifier la conquête romaine -, occulte quelque peu ce témoignage strabonien et n'en propose pas une véritable exégèse, à la lumière par exemple des pratiques historiographiques de cet auteur, y compris dans le livre III. Par ailleurs, les études récentes sur la géographie antique et la bibliographie proprement strabonienne, qui s'est considérablement entichie ces derniers temps, sont peu prises en compte. On regrettera aussi que l'auteur n'ait pas profité de cette nouvelle édition 
pour revoir certains chapitres, celui sur Tartessos en particulier, à propos duquel on a beaucoup publié depuis 1981. Quoi qu'il en soit, ceux qui s'intéressent au passé de la péninsule ibérique, mais aussi ceux qui sont amenés à envisager, à travers les témoignages des auteurs gréco-romains, des réalités extérieures au monde classique, tireront profit des travaux qui sont réunis dans ce volume. En portant sur les civilisations indigènes un regard qui volontairement se démarque des idées reçues et met en œuvre de nouvelles méthodes, J.C. Bermejo Barrera évolue sans nul doute hors des sentiers battus.

Véronique KRINGS

(Université de Liège)

\section{Christine BREUER, Reliefs und Epigramme griechischer Privatgräber. Zeugnisse bürgerlichen Selbstverständnisses vom 4. bis 2. Jabrbundert v. Chr., Köln-Weimar-Wien, Böhlau, 1995. 1 vol. 20,5 x 28 cm, 151 p., 51 ill., 8 tableaux (Arbeiten zur Archäologie). ISBN: 3-412-15893-3.}

À partir du moment où, cultivant le souvenir d'un défunt, on a voulu se rappeler avec précision où se trouvaient ses restes, le besoin s'est fait sentir de marquer cet emplacement par un repère bien visible. Là où il n'était fourni ni par la nature ni par le résultat de quelque action humaine, on a recouru à la pierre, matière solide et durable, sous la forme d'un bloc, d'abord grossier, puis ouvré avec soin jusqu'à devenir un monument, tantôt sobre, tantôt imposant. La variété la plus commune en est la stèle, portant au minimum le nom du disparu, du moins après que les Grecs eurent acquis une pratique suffisante de l'écriture alphabétique. Des développements ont suivi. Au nom du défunt ont pu s'en ajouter d'autres, ceux de membres de sa famille ou d'amis, mais aussi un texte, couramment composé en vers, destiné à le faire mieux connaître ou estimer du passant; d'autre part, le support matériel n'a pas tardé à s'enrichir d'une décoration, souvent d'un relief artistiquement réalisé.

Ainsi naquirent deux modes d'expression, l'un littéraire, l'autre plastique, qu'il est tentant de confronter dans ce qu'ils avaient mission d'exprimer. Quiconque s'intéresse tant soit peu à la question aura avantage, désormais, à utiliser le volume de Mme Christine Breuer. Elle y reproduit, avec de légères modifications, la dissertation doctorale qu'elle a soutenue en 1993 à l'Université de Cologne. Dans son mémoire de maîtrise demeuré inédit (Munich, 1988), elle avait étudié les deux modes, pour la période hellénistique, dans leur commune liaison avec le tombeau. Elle y considérait: l'information relative au mort en tant que devant assurer la pérennité de son souvenir, puis les moyens fournis à cette fin par l'épigramme et par la figuration, puis encore les jugements de valeur que l'épigramme énonce pour le caractériser. Ici, la perspective a sensiblement changé. Ce ne sont plus les réactions et les sentiments éveillés par la vue du monument funéraire qui sont mis en lumière, mais le fait que les deux modes témoignent de la façon dont l'individu se situait publiquement devant ses contemporains - toujours en dépendance du contexte social, ce qui introduit dans la question une dimension historique.

Le début de l'exposé a trait au «conditionnement de la conscience civique et de sa représentation dans le relief et l'épigramme funéraires par le rapport établi entre l'individu et la Polis». Une large place y est accordée à la $\delta \varepsilon \xi \hat{i} \omega \sigma ı \varsigma$, à la « poignée de main », motif usuel dans les reliefs et particulièrement riche. En elle, on a affaire sans 